\title{
LA OFICINA DE DESTILACIÓN DE AGUAS Y ACEITES DEL REAL SITIO DE ARANJUEZ (1564-1721)*
}

\author{
M. ${ }^{a}$ Luisa de Andrés Turrión
}

Cátedra de Historia, Facultad de Farmacia, UCM.

\section{Pilar García de Yébenes Torres}

Facultad de Farmacia, UCM.

\section{RESUMEN}

En el mes de septiembre de 1564, la Oficina de Destilación del Real Sitio de Aranjuez inició oficialmente su funcionamiento bajo el control de la Casa Real de S.M. Felipe II. La Junta de Obras y Bosques, organismo encargado de la administración y gobierno de las casas y jardines reales, así como de las nuevas construcciones de la Casa Real española, se ocupó de su financiación y control. El gobernador de Aranjuez y los médicos de Cámara fueron responsables de la selección sucesiva de los destiladores, los cuales recibieron sus nombramientos como criados reales mediante una Real Cédula firmada por el monarca.

En este artículo se describen las tareas destilatorias que allí se realizaron y los destiladores que las llevaron a cabo hasta su desaparición, en 1721. La Real Botica de Felipe V asumió, en ese año, el trabajo de la destilación.

\section{SUMMARY}

In September of 1564, the agency of distillation of the Royal Place of Aranjuez began its operation under the control of the Royal House of H.M. Felipe II. The Works and Woods Board, body entrusted with the management and the keeping of the royal houses and gardens, as well as of the new buildings of the Spanish Royal House, dealt with its financing and control. The governor of Aranjuez and the doctors of Chamber were in charge of the successive selection of the distillers, who got their appointment as royal servants by a Royal Doccument signed by the monarch.

In this article, the works of distillation that were made there and the distillers, that carried at them, until its disappearance, in 1721, are described. The Royal Pharmacy of Felipe V assumed, in that year, the work of the distillation.

* Financiado con cargo al proyecto de investigación PS94-0028 del Programa Sectorial de Promoción General del Conocimiento. 
M. ${ }^{a}$ LUISA DE ANDRÉS TURRIÓN y PILAR GARCÍA DE YÉBENES TORRES

\section{INTRODUCCIÓN}

Es conocido por todos el interés del monarca español Felipe II (1527-1598) por la alquimia ${ }^{1}$ desde su vertiente más materialista, ansiando en que ésta hiciera posible la fabricación de oro para sus costosos proyectos imperiales. Más tarde, y receloso de vanos intentos, mantuvo su confianza en la suposición de que la alquimia podría ofrecerle otra recompensa: los poderes curativos de aguas, aceites y quintaesencias, y aquí las esperanzas de Felipe II parece que fueron fuertes y constantes. Su Casa Real contrató, bajo la supervisión de los médicos de Cámara, a expertos destiladores que trabajaron para el monarca desde que éste se instaló definitivamente en la villa de Madrid. Algunos de ellos ejercieron en la oficina de destilación de Aranjuez, de la que hablaremos a continuación.

\section{LOS PRIMEROS AÑOS DE FUNCIONAMIENTO (1564-1602)}

Cuando los Reyes Católicos incorporaron a la corona los bienes de las órdenes militares, Aranjuez, que lo fue de la orden de Santiago, se convirtió en residencia de los monarcas españoles. Tanto Fernando el Católico como Carlos V lo atendieron, pero fue Felipe II, al establecer a finales de 1561 su corte en Madrid, quien tomó un interés especial por aquel $\mathrm{Sitio}^{2}$, encargando trabajos de reforma y acondicionamiento que no fueron continuados hasta muchos años después. La conocida inclinación del monarca por la Botánica quedó demostrada con la creación y mejora de las huertas y jardines de Aranjuez, sobre todo de uno de ellos, el jardín de la Isla, por las

\footnotetext{
1 Existe una extensa bibliografía dedicada a este estudio. Podemos mencionar los trabajos de:

Goodman, D. (1990), Poder y penuria. Gobierno, tecnología y ciencia en la España de Felipe II, Madrid.

LÓPEZ PIÑERO, J.M. (1976), Ciencia y sociedad en la España de los siglos XVI y XVII, Madrid.

PARKER, G. (1984), Felipe II, Madrid.

PUERTO SARMIENTO, F.J. (1997), «La panacea áurea. Alquimia y destilación en la corte de Felipe II (1527-1598)», DYNAMIS 17, pp. 107-140.

RODRÍGUEZ MARÍN, F. (1927), Felipe II y la alquimia, Madrid.

RuIZ, J. (1977), «Los alquimistas de Felipe II», Historia 16, II (12), pp. 49-55.

Aportaciones de diferentes autores (1994) La ciencia en el Monasterio de El Escorial. Actas del Simposium (1/4-IX-1993). Colección del Instituto Escurialense de Investigaciones Históricas. n³3. San Lorenzo de El Escorial (Madrid).

2 Una Real Cédula de S. M. del año 1561 aprobaba la Instrucción General para el Gobierno de Aranjuez, en la que se exponían los cargos oficiales del Real Sitio, sus responsabilidades y se encargaba que, cada año, se hiciera una visita general del Sitio para controlar su buen funcionamiento. ARCHIVO GENERAL DEL PALACIO REAL DE MADRID (A.G.P.). Cédulas Reales. Tomo II. Año 1561. p. 188.

$\mathrm{Ni}$ en esta Instrucción, ni en la siguiente de 1563 , se hace referencia alguna a la existencia de una oficina de destilación ni de sus destiladores.
} 
condiciones naturales que le aportaba el río Tajo, del que se hizo una canalización de sus aguas alrededor de la isla. El arquitecto Juan Bautista de Toledo y los jardineros Jerónimo Algora y Juan Holbeque ${ }^{3}$ realizaron nuevos diseños para este jardín, que fueron del gusto de Felipe II, comenzando a construir diversas fuentes e instalando a la entrada del mismo, fuera del corral de los Álamos y junto al palacio viejo, una oficina de destilación de aguas y aceites ${ }^{4}$.

La Junta de Obras y Bosques, responsable de la administración patrimonial del Real Sitio, se ocupó de la financiación y del control de la oficina de destilación ${ }^{5}$. El fiscal de la Junta, de acuerdo con el gobernador de Aranjuez, asignó el presupuesto anual teniendo en cuenta los salarios de sus empleados, las tareas de mantenimiento y la adquisición de plantas, leña y otros materiales. La Real Hacienda tenía en Aranjuez un mayordomo y pagador que recibía en forma de «libranzas» y de «recaudos» las cantidades que, más tarde se pagarían por vía de la Contaduría de Aranjuez en la misma Junta.

La oficina de destilación contó, al menos, con tres torres de destilación (de las que una de ellas era la mejor) y cinco calderas de cobre (dos grandes y tres pequeñas), que daban fuego a las torres y adherentes ${ }^{6}$. Más de doscientas arrobas de vidrio fueron empleadas para la elaboración del material con el que allí se trabajó, entre redomas, alambiques, cabezas y otros géneros para el ejercicio de la destilación?. Única-

3 Jardinero flamenco, natural de Turnay, que trabajó en los jardines de Aranjuez desde el 1-4-1561, aunque hasta esa fecha lo hizo también para el monarca Felipe II: «... hasta el dicho día $1^{o}$ de abril está pagado de dineros míos por Gautier Vanrroselar». Nómina de los jardines de Aranjuez. Madrid 15-61561. A.G.P.. Cédulas Reales. T. 2, p. 122-125 vo.

4 En 1636 se propuso su traslado, por motivos de reforma en el palacio, al edificio que ocupaba una antigua armería junto a la llamada «sierra del agua», pero jamás llegó a efectuarse. Orden del Superintendente general de las obras Reales, Marqués de Torres, fechada el 24-febrero-1636. En ÁLVAREZ DE Quindós, J. (1804), Descripción histórica del Real Bosque y Casa de Aranjuez. Madrid. p. 198.

En 1717 se reintentan las reformas del palacio y se vuelve a hablar de la Armería como lugar de traslado de la oficina de la destilación. Informes del fiscal de Obras y Bosques. 1722. A.G.P.. Aranjuez. Caja 14142. Expedientes sobre la Destilación de Aranjuez.

A.G.P., Cédulas Reales. Tomo XII. En GonZÁLEZ, A. (1986) «El Palacio Real de Aranjuez: una nueva estructura entre 1626 y 1750», Reales Sitios. 89 (57-64). Madrid.

5 Los Austrias contaban para la administración y gobierno de su patrimonio con una organización compleja, cuyo organismo de decisión visible era la Junta de Obras y Bosques; organismo que se encargaba del mantenimiento y reformas de sus casas y jardines, así como de las nuevas construcciones.

6 Conocemos estos datos por las obras de arreglo de la destilación de Aranjuez realizadas en octubre y noviembre de 1674. A.G.P.. Sección Administrativa. Leg. 631.

7 Con 200 arrobas de vidrio pudieron tener en la destilación de Aranjuez unas 1.300 piezas, si éstas se encargaron con piezas modelo similares a las de la botica de El Escorial, años después, de 4,5 libras de vidrio cada una, es decir, unos 2 kilogramos. ARCHIVO DEL MONASTERIO DE EL ESCORIAL, 11-14, folio 8v., en LÓPEZ GAJATE, J. (1994). La botica de San Lorenzo de El Escorial. La ciencia en el Monasterio de El Escorial. Actas de el Simposium (1/4-IX-1993). Colección del Instituto Escurialense de Investigaciones Históricas n³. San Lorenzo de El Escorial. Madrid. p. 335. 
mente tres llaves permitían el acceso a la instalación y éstas se encontraban en poder de tres personas: el gobernador de Aranjuez, el contador de la Junta de Obras y Bosques y el destilador de S.M..

La oficina de Destilación de Aranjuez comenzó a funcionar en 1564 bajo el control de dos destiladores flamencos, Francisco Holbeque y su hermano Juan, citado anteriormente, que aunque contratado como jardinero, era experto en el oficio ${ }^{8}$.

Las tareas de la destilación comenzaban en primavera, «en época de rosa y flores», preparando aguas y aceites medicinales de una gran variedad de plantas, hierbas y flores aromáticas para el uso particular de la Familia Real y para el abastecimiento de las boticas de S.M. y Altezas, en la corte 9 .

En 1567, Francisco Holbeque obtuvo el nombramiento oficial de destilador de S.M. ${ }^{10}$

La plaza de destilador de S.M. era de designación real, puesto que el individuo que la ocupaba se convertía en criado del rey, siendo imprescindibles informes favorables del Tribunal del Protomedicato, organismo responsable de todas las profesiones sanitarias, y del gobernador de Aranjuez. Una Real Cédula hacía efectivo el nombramiento a la vez que señalaba obligaciones y salario a disfrutar.

El destilador encargado de la oficina de Aranjuez tenía la obligación de ocuparse de «todas las cosas de su profesión» que, por mandato directo del monarca o de sus ministros, le fuesen ordenadas. Debía residir obligatoriamente en Aranjuez, pero acudiría cuando se le ordenara a algunas localidades, especialmente al Monasterio de San Lorenzo El Real y a la villa de Madrid; también a las casas reales de El Pardo, Bosque de Segovia, Aceca y Alcázar de Toledo, sin que por ello se le tuviese que pagar salario extra; si las órdenes le obligaban a alejarse del entorno de estos lugares, sí se le abonarían los gastos que tuviera.

El salario del primer destilador de S.M., Francisco Holbeque, fue de 300 ducados anuales y numerosas concesiones y nombramientos retribuidos. Sus sucesores en la destilación cobraron siempre 200 ducados anuales más 50 fanegas de trigo, otras tantas de cebada y alojamiento en el Real Sitio de Aranjuez.

Los cuidados básicos consistían en que ningún horno se descargara ni se agotara el suministro de agua. Para ello, además del destilador trabajaba un ayudante y se

\footnotetext{
8 No existe nombramiento en Cédula Real de Juan Holbeque como destilador, aunque parece que desempeñó funciones de destilador en Aranjuez desde que comenzó a funcionar la Oficina de Destilación, en 1564, y hasta su muerte. ÁlVAREZ DE QuiNDós, J. (1804),(oc) en (4). pp. 283-284.

9 En 1619, una Real Cédula concedía que se dieran aguas de la destilación de Aranjuez al boticario de aquel Sitio hasta 50 ducados. A.G.P.. Cédulas Reales. a. 1619, t. XI, f. 774 v.

10 Francisco Holbeque fue nombrado criado real encargado de la destilación para el servicio de los reyes por R.C. 3-3-1567 con efectos desde el 1-9-1564 en que comenzó a trabajar. A.G.P.. Cédulas Reales. T. III. p. 48 .
} 
ordenó a todos los mozos ordinarios solteros de huertas y plantíos de Aranjuez que, cuando no tuvieran trabajo, ayudaran a la destilación ${ }^{11}$.

El oficial ayudante de la destilación accedía a la plaza, bien formándose como aprendiz al lado del destilador hasta que éste solicitaba su nombramiento como ayuda, o bien porque el propio destilador lo elegía por las buenas referencias que tuviera de él. Una Real Cédula hacía efectivo el nombramiento y le asignaba salario y obligaciones. El sueldo del ayudante era de 3 reales de vellón (rv) al día (100 ducados al año) y debía residir en Aranjuez. Hubo en estos primeros años dos ayudantes, ambos sobrinos de Holbeque: Juan del Valle y Juan de Sanchois.

Tras el fallecimiento de Francisco Holbeque, en 1595, le sucedieron en el cargo de destilador Juan de Sanctén ${ }^{12}$, Juan Ausnero ${ }^{13}$ y Juste Fraye ${ }^{14}$ sucesivamente.

\section{LA DESTILACIÓN DE ARANJUEZ Y LA NUEVA BOTICA REAL. LA FAMILIA FORTE}

En 1594, los médicos de Cámara organizaron una nueva Real Botica para S.M. Felipe II que, por primera vez, estuvo situada en el propio Alcázar compartiendo con los demás oficios un lugar en la Casa del Tesoro. El oficio de la botica contó con un jefe o boticario mayor, cuatro ayudas (boticarios examinados), cuatro mozos de oficio (boticarios examinados). Un destilador (no perteneciente a la plantilla de la Real Botica) la surtía de aguas y aceites medicinales, remedios considerados esenciales en aquellos momentos. Ambos, boticario mayor y destilador, estuvieron a las órdenes de los médicos de Cámara (también protomédicos de S.M.) que se encargaban de la organización científica de la Botica ${ }^{15}$.

Giovanni Vincenzio Forte ${ }^{16}$, de origen napolitano, al que años antes había contratado Felipe II como destilador del Alcázar de Madrid, ocupó esta plaza contando con

11 A.G.P.. Sección Libros de Registro, $N^{o}$ 6673. Noticias antiguas del Real Heredamiento de Aranjuez, por D. Pedro Fco. de la Peña. Libro en el que se copian varias instrucciones, autos y Reales Cédulas tocantes al gobierno y administración de la Real Hacienda, desde 1563 a 1691. Las copias van firmadas y autorizadas en 1692, fecha en que se compuso el libro.

12 Nombramiento de destilador por R.C. de 21-10-1595. Sirvió hasta 1598. A.G.P.. Cédulas Reales. T. IX. p. $9 v^{o}$.

13 Nombramiento de destilador por R.C. de 11-4-1598. Falleció en 1602. A.G.P.. R.C.. T. IX. p. 313 bis $v^{o}$.

14 Nombramiento de destilador de la botica de El Escorial por R.C. 27-9-1595, y destilador de Aranjuez en 11-4-1598. A.G.P.. R.C.. T. IX. p. 314.

15 A.G.P., Sec. Adm., Leg. 429.

16 La Real Cédula exponía su nombramiento «para destilar aguas y aceites y hacer las demás cosas anejas y concernientes a su oficio para la provisión de nuestra botica». A los pocos meses le fue concedido el servicio de un mozo, su hijo Valerio, para que le ayudara en su oficio. A.G.P.. Reales Cédulas. T. V, F. $256 v^{\circ}$. 18-abril-1579.

El gobernador de Aranjuez informó el 23 de agosto de 1679 sobre los Forte y decía: «Joan Vicenzio Forte sirvió en el oficio de destilador de las aguas y aceites que se benefician en el Real sitio de Aranjuez para la Botica de S.M. durante algunos años». A.G.P.. Expedientes personales, C ${ }^{a} 373 / 6$. 


\section{M. ${ }^{a}$ LUISA DE ANDRÉS TURRIÓN y PILAR GARCÍA DE YÉBENES TORRES}

la ayuda de su hijo Valerio y ambos quedaron vinculados, desde entonces, con la Real Cámara y con la propia Real Botica.

Durante ocho años se mantuvo esta situación por la que la Real Botica conseguía sus aguas y aceites medicinales del destilatorio de la corte (en Madrid) y de la oficina de destilación de Aranjuez.

En 1602, al producirse el fallecimiento del destilador de Aranjuez, Valerio Forte ${ }^{17}$ fue nombrado para desempeñar ambas plazas, quedando obligado a alternar sus estancias entre Aranjuez y Madrid, responsabilizándose de los dos destilatorios y contando para ello con dos ayudantes, uno que residiría en aquel Real Sitio y otro en la corte $^{18}$. Se iniciaba una saga de destiladores que durante cuatro generaciones trabajaron para la Casa Real. Valerio, Vicencio ${ }^{19}$, Bernabé ${ }^{20}$ y Vicente Forte ${ }^{21}$ ocuparon secuencialmente la plaza de destilador de Aranjuez, dando cuenta de su trabajo al gobernador de aquel Sitio y a los médicos de Cámara que velaban por la calidad de las medicinas de la Botica Real. Con dedicación exclusiva a su empleo, tenían prohibido realizar cualquier trabajo ajeno al servicio de S.M. Su salario consistió en 360 ducados anuales, que aunaba el sueldo de destilador de Aranjuez (200 ducados/año) con el de destilador del Alcázar (160 ducados/año). El gobernador de Aranjuez les otorgaba vivienda en el Real Sitio, 50 fanegas de trigo y 50 de cebada y, por el Guardarropa de la Cámara Real se les daba un vestido, cada año, por valor de 80 ducados.

Cada uno de estos destiladores pudo nombrar directamente a sus dos ayudantes los cuales, pese a sus diferentes destinos, cobraban el mismo salario de 3 reales al día ${ }^{22}$.

17 Comenzó a trabajar en la destilación del palacio de Madrid, ayudando a su padre Juan Vicenzio. Al regresar éste a su tierra y quedar vacante la plaza, la ocupó Valerio. Informe del gobernador de Aranjuez de 23-8-1697 sobre los Forte. A.G.P.. Expedientes personales 373/6.

Una Real Cédula de 6-8-1602 lo nombró para ambas plazas, al producirse el fallecimiento de Joan Ausnero. A.G.P.. Cédulas Reales. T. X. p. $319 v^{o}$.

18 Tuvo como ayudantes, en Aranjuez, a Horacio López y Sebastián Rugero; en Madrid, a Salvador Brun y Bernabé Forte (su hijo).

19 Nombrado destilador al morir su padre Valerio por Real Cédula de 30-8-1633. A.G.P.. Cédulas Reales. T. XIII. p. 129.

Tuvo como ayudantes, en Aranjuez, a Sebastián Rugero y Bernabé Forte (su hermano) y, en Madrid, a Julio Soleta y Antonio Sánchez de Vidaurreta.

20 Fue destilador interino desde la muerte de su hermano Vicenzio, en 1661, hasta 1672 en que su sobrino Vicente la ocupó, por tenerla en propiedad. A.G.P.. Cédulas Reales. T. XV. p. $114 v^{o}$.

Tuvo como ayudantes a Antonio Sánchez y a su hijo Bernabé Forte Ríos.

21 Nombrado destilador el 3-3-1672. A.G.P.. Cédulas Reales. T. XV. p. 406.

Tuvo como ayudante en aranjuez a Miguel García de Paredes.

22 El salario del ayuda de Madrid lo pagaba el oficio de la Furriera. El oficio de la Furriera y Aposentador de palacio tenía a su cargo y servía todos los muebles, pinturas, alumbrado de cera a las habitaciones reales, aseo y limpieza de los reales cuartos, suministro de leña y reparto de habitaciones para todos los criados de S.M. en Madrid y en los Reales Sitios. 
La familia Forte controló la oficina de destilación de Aranjuez desde 1602 hasta 1681, alcanzando el prestigio que la hizo merecedora de ser considerada imprescindible para el buen funcionamiento de la Real Botica. Tal y como señalaban las Reales Cédulas, la misión de los destiladores consistía en destilar, durante el tiempo apropiado, toda clase de aguas y durante todo el año, jarabes y todo aquello que la Real Botica les sugiriera. Su importancia la demostraba el propio boticario mayor cuando, apremiando la realización de arreglos en aquella oficina, declaraba: «De no remediarse habrá de cerrar la Botica por consistir lo más del gasto de ella en lo que se destila en Aranjuez» ${ }^{23}$. La Botica reguló anualmente los pedidos que se sirvieron desde Aranjuez. Álvarez de Quindós señala que «en el año de 1620 se destilaron, además de lo acostumbrado, veinte arrobas de agua de escorzonera, veinte de borraxas, veinte de lengua de buey, veinte de chicorias, diez y seis de agua rosada, diez y seis arrobas de llantén y veinte arrobas de las quatro aguas cordiales; todo lo cual se reguló necesitarse para surtido de la Botica del rey» ${ }^{24}$. Por otra parte, la instrucción que se dictó en 1649 para la Botica Real y sus oficiales, obligó a la oficina de destilación de Aranjuez a mantener sus envíos habituales de aguas y aceites a los que sumaría los de aguardiente común y rectificado para el gasto de la Real Botica. Esta instrucción ordenaba al destilador mayor y su ayuda en Aranjuez, tener un particular cuidado en la destilación de las citadas aguas y en su traslado a la corte. El boticario mayor se responsabilizaba de su limpieza y mantenimiento en la Botica y de ordenar su reposición cuando fuera necesario ${ }^{25}$.

Todos los veranos, el destilador de Aranjuez pedía al oficio del Guardajoyas de S.M. «lo necesario para aderezar las aguas de olor que se gastaban en la Cámara del rey»; se trataba de tres sustancias oleosas: ámbar, almizcle y algalia con las que elaboraba un preparado de buen olor y de acción, más o menos, desinfectante para rociar la cámara del rey y las demás piezas de su real cuarto alto, bajo y bóvedas, como también las escaleras y pasadizo de la Encarnación ${ }^{26}$.

\footnotetext{
23 Informe de Juan de Moya, jefe de la Real Botica, a S.M. Madrid, 12-11-1674. A.G.P.. Secc. Adm. Leg. 631 .

24 Álvarez de Quindós, J. (1804), o.c. en (4). p. 224.

25 A.G.P.. Sección Histórica. Caja 54. Etiquetas y ceremonias. Etiquetas de la Real Cámara, 18 de abril de 1649. En GARCÍA DE YÉBENES TORRES, P. (1994) La Real Botica durante el reinado de Felipe V (1700-1746), Tesis doctoral inédita, D.F. y T.F, Facultad de Farmacia. U.C.M., Madrid, pp. 373-382.

26 Vicente Forte, destilador mayor, solicitaba se le libraran 1.200 rv. para comprar sustancias que no tenía el Oficio de Guardajoyas. A.G.P.. Sec.. Adm.. leg. 631. Empleos de la Real Casa. Destiladores de Cámara.
} 
IV. LA OFICINA DE DESTILACIÓN DE ARANJUEZ ES CONTROLADA POR LA REAL CÁMARA DE S.M.. (Resolución Real, 4-3-1686)

Tras la muerte de Vicente Forte (1679), distintas circunstancias (la repentina muerte de Alberto Roda ${ }^{27}$, su sucesor, que sólo ocupó un año la plaza y las denuncias sobre el absentismo laboral del destilador que cubrió de nuevo la vacante, Francisco Gadea ${ }^{28}$ ), provocaron una situación de incertidumbre y la consiguiente publicación de una Resolución Real (4-3-1686) en la que la Real Cámara de S.M. asumía el control de la destilación de Aranjuez, de la misma forma que lo venía haciendo con la Real Botica, otorgando a aquélla el calificativo de Oficio Real. Todas las cuestiones relativas a la oficina de destilación, sobre todo en lo concerniente a la elección de su personal, quedaban sometidas a la jurisdicción de la Real Cámara y, por lo tanto, a la del sumiller de $\operatorname{corps}^{29}$. Miguel García de Paredes, mozo de oficio de la Real Botica y experto en destilación por sus años como interino y ayuda de la misma, fue nombrado destilador mayor ${ }^{30}$.

Figura 1. Organización del Real Oficio de la Destilación. 1602.

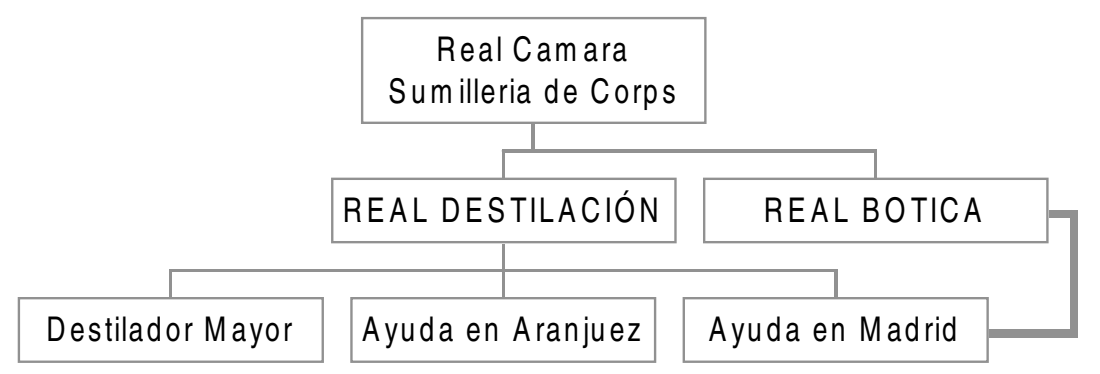

\footnotetext{
27 Boticario de Zaragoza, nombrado destilador el 30-6-1680. A.G.P.. Cédulas Reales. T. XVI. p. $271 v^{o}$. Tuvo como ayudante a Miguel García de Paredes en Aranjuez.

28 Sirvió de entretenido, mozo de oficio (20-9-1657) y ayuda (31-3-1666) de la Real Botica. A.G.P.. Expedientes personales, 383/20.

Nombrado destilador el 16-2-1683. A.G.P.. Cédulas Reales. T. XVI. p. 374.

Tuvo como ayudantes, en Aranjuez, a Miguel García de Paredes y, en Madrid, a Francisco Negrón.

29 El 4 de marzo de 1686 se comunicó la Resolución Real en los siguientes términos: «Siendo parte tan esencial de la real botica la destilación de las aguas, que debe reputarse de un mismo oficio, toca al sumiller de corps consultar personas para él», quedando bien distintos empleos y consignaciones. Resolución de S.M. comunicada por el Conde de Monterrey. A.G.P.. Sec. Adm.. leg. 631. Empleos de la Real Casa. Destiladores de Cámara.

30 Nombrado por Real Cédula de 8-8-1685. A.G.P.. Cédulas Reales. T. XVI. p. $585 v^{o}$.

Tuvo como ayudantes, en Aranjuez, al proveedor de la Destilación Gregorio Bárcenas y a Miguel Alfonso García de Paredes y, en Madrid, a Francisco Negrón y Miguel de hito y Robles.

Podemos observar la gran interrelación de los dos oficios. A.G.P.. Sec. Administrativa. Leg. 649.
} 
La independencia de los oficios de la Destilación y de la Real Botica fue clara y cierta, aunque mantuvieron «íntimos» nexos de unión; sirva como ejemplo de esta relación el hecho de que el ayuda con destino en Madrid tenía la misión de realizar las operaciones urgentes de destilación de aguas en la propia Real Botica pero, a la par, era considerado como ayuda de ésta.

Figura 2. Petición de Caballerias para el transporte de las aguas destiladas.

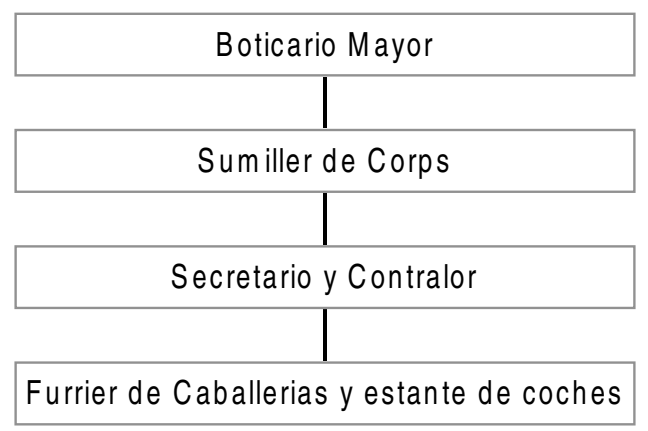

Todos los individuos vinculados a este oficio, tanto el destilador mayor como sus ayudas, debían ser boticarios examinados. La elección de estos cargos se realizaba de forma similar al resto del personal de la plantilla real, teniéndose en cuenta su valía profesional pero también sus buenas relaciones con las jerarquías administrativas de la Casa Real ${ }^{31}$.

La principal responsabilidad del destilador mayor y, ciertamente, el objeto de la existencia del Oficio de la Destilación, continuó siendo la obtención de aguas destiladas, cordiales o no, y de aceites medicinales. Dos veces por semana, el boticario

31 La elección podía hacerse aleatoriamente o pensarse en el cargo como recompensa o gracia hacia determinadas personas. A esta conclusión nos conduce la forma de actuar Miguel García de Paredes, destilador mayor, que en el año 1689 solicitaba para su hijo (Miguel Alonso García de Paredes) la plaza de destilador que él mismo ocupaba, para el final de sus días. En el año 1707, Miguel Alonso García de Paredes fue nombrado destilador mayor, sustituyendo a su padre fallecido, comunicándose y registrándose el nombramiento por el sumiller de corps el 23 de agosto de 1707. Según consta por el extracto del memorial del destilador mayor, de 20 de agosto de 1689, dirigido al sumiller de corps (Duque de Pastrana). Pasados unos años, el 18 de octubre de 1693, volvió a solicitar la «futura» del oficio de destilador mayor de Aranjuez, enviando el memorial al sumiller de corps (el Conde de Benavente). En realidad estas peticiones se harían periódicas. Y como todos los empleados de SS.MM., haría súplicas de distinta entidad: el 4 de mayo de 1691, solicitaba que la mitad del goce que tenía se le diera a su esposa, Ana Dávila, para después de sus días. A.G.P.. Libro de Registro $n^{\circ} 547$. 


\section{M. ${ }^{a}$ LUISA DE ANDRÉS TURRIÓN y PILAR GARCÍA DE YÉBENES TORRES}

mayor solicitaba el traslado de aguas desde Aranjuez a la Corte siguiendo los trámites que la burocracia le exigía. Previa petición del boticario mayor, a la mayor brevedad posible, eran enviadas mulas suficientes para recoger las aguas ${ }^{32}$.

Como misión y responsabilidad de los ayudas de la Destilación (con destino en Madrid) aparecían los siguientes puntos: cuidar de la reposición de las aguas; cargar y descargar las arcas que iban y venían al real sitio; colar las aguas en verano («porque con el calor se suelen desvanecer»); rociar el cuarto de S.M., en ausencia del destilador mayor; destilar cualquier cosa que se ofreciera en la botica, o para cualquier criado de S.M.; suplir las aguas que por algún accidente no se pudiera ir con las acémilas a por ellas ${ }^{33}$.

La función que desempeñó habitualmente el personal de la Destilación de proceder a la desinfección y desinsectación de las habitaciones reales, tal y como se practicaba en la época, rociándose con vinagre de «juncia» los cuartos, precisa algunas matizaciones ${ }^{34}$. Cuando desde las instancias reales se veía la necesidad de proceder a la operación del «rociado», se daba aviso al Gobernador de Aranjuez, pidiéndole ordenara al destilador de Aranjuez que, él y su ayuda, vinieran a Madrid con las aguas y vinagres de olor a «regar» los cuartos ${ }^{35}$. El destilador mayor llegaba a la Corte a finales de junio, ocupando todo el verano en rociar las habitaciones, quedándose en Madrid a residir. Los cuartos de la Reina eran rociados por el ayuda de destilador que residía siempre en la Real Botica ${ }^{36}$.

El sueldo de los empleados de la destilación en Aranjuez continuó a cargo de la Junta de Obras y Bosques de Aranjuez ${ }^{37}$. El destilador mayor recibía anualmente 400 ducados, 50 fanegas de trigo, 50 fanegas de cebada, casa en el Real Sitio, 100 duca-

\footnotetext{
32 Para transportar estos productos desde Aranjuez a Madrid, se precisaba el servicio de otros empleos de la Real Casa; Así, las Reales Caballerizas proveían de las acémilas, llamadas de regalo, necesarias para la conducción de las aguas. A.G.P.. Aranjuez. Caja 14142. Expedientes sobre la Destilación. 1722. Informe del Fiscal de la Junta de Obras y Bosques.

A.G.P.. Sec. Adm. Leg. 690.

A.G.P.. Sec. Adm.. leg. 631. Empleos de la Real Casa. Destiladores de Cámara.

33 Según informe del boticario mayor Juan de Moya Salazar de 24 de enero de 1693. A.G.P.. Leg. 631.

34 Esta labor estaba retribuida independientemente del salario del que la realizara. En las postrimerías del reinado de Carlos II, el trabajo de rociar los cuartos reales era pagado por días empleados en dicho servicio, abonados de los caudales de la Real Cámara o por la Secretaría del Despacho, en la cantidad de 6 rv/día. Y este goce, extraordinario, siempre sería el mismo, se realizara en Madrid o cualquier otro real sitio A.G.P.. Sec. adm.. Leg. 631. Empleos de la Real Casa. Destiladores de Cámara y Resolución de S.M. en el sentido expresado, de fecha 9 de septiembre de 1714. A.G.P.. Libro de Registro $n^{\circ} 4501$. Sumillería de Corps. 1707-1745. Folio 33 vto.

35 A.G.P.. Sec. Adm.. leg. 631. Empleos de la Real Cámara. Destiladores de Cámara. Comunicaciones de 1 de julio de 1685 y 21 de junio de 1686.

36 Informe al grefier de 6 de julio de 1702. A.G.P.. Leg. 339. Felipe V. Real Cámara.

37 A.G.P.. Libro de Registro $n^{\circ}$ 4501. Sumillería de Corps. Extracto de Consultas y resoluciones. $1707-1745$
} 
dos por casa de aposento y 80 ducados de vestuario en el mercader de S.M.. Un ayuda de la destilación continuaba recibiendo 3 rv al día.

Figura 3. Comunicaciones necesarias para hacer efectivo el cobro de un salario en la destilacion, despues de un nombramiento.

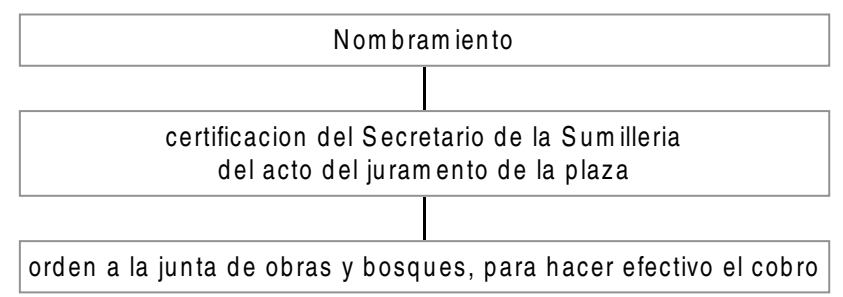

Prácticamente finalizado el siglo XVII sucedieron dos circunstancias que merecen la pena destacarse. En primer lugar, el viejo destilatorio de la corte situado en la calle de Santo Tomás de Madrid, donde comenzó a trabajar Giovani Vincenzo Forte en tiempos de Felipe II y donde continuaron haciéndolo, posteriormente, todos los ayudas de la destilación con destino en Madrid, fue trasladado (1692-1693) a una sala contigua a la Real Botica en la Casa del Tesoro por petición del boticario mayor. De ese modo, podían compaginarse mejor las tareas comunes de ambos oficios que algunos empleados realizaban ${ }^{38}$. Por otro lado, el estado de la oficina de la destilación de aguas medicinales de Aranjuez era tan lamentable que Miguel García de Paredes, destilador mayor, necesitó, tras numerosas solicitudes, reparar las cuatro calderas que conformaban el elemento principal $^{39}$.

38 Olalla, C. (1975). La farmacia y su museo. El Palacio Real de Madrid. Madrid. pp 413-430.

39 Por las continuas quejas del destilador mayor se mandó al maestro de obras de Aranjuez (Bernabé González) reconociera las estancias e informara. En el informe que presentó explicaba las necesidades: «arreglo en los pares de la armadura y reforzar una pared; además las cuatro calderas estaban muy gastadas, habiéndolas que echar suelos y cobre en paños y tapadores, sobre todo en dos de ellas». Informe de 12 de febrero de 1698. A.G.P.. Sec. Administrativa. Leg 631. Empleos de la Real Casa. Destiladores de Cámara.

El informe del sumiller de corps, el Conde de Benavente, a S.M., reflejando las quejas del Destilador Mayor, aparece registrado en A.G.P.. Libro de Registro $n^{\circ}$ 557, folio 86/63 vto.

Acercándose la primavera y la necesidad de preparar las aguas para la Real Botica, pedía se arreglara la Destilación. A petición del sumiller de corps (Conde de Benavente), a 24 de febrero de 1698, se entregaron al Gobernador de Aranjuez 200 Ducados, los necesarios para la composición, principalmente de las calderas. La petición del destilador mayor pasó por manos del Gobernador de Aranjuez, Francisco de Castro, y fue éste quien, además de lo expuesto, solicitó al sumiller de corps, el 14 de febrero de 1698 , recibir una cantidad de dinero para pagar a quienes suministraban flores, hierbas y recipientes. A.G.P. Sec. Adm. leg. 631. 


\section{M. ${ }^{a}$ LUISA DE ANDRÉS TURRIÓN y PILAR GARCÍA DE YÉBENES TORRES}

\section{TRASLADO DE LA OFICINA DE LA DESTILACIÓN Y EXTINCIÓN DEL OFICIO. (Resolu- ción Real 8-3-1721)}

Con el comienzo del reinado de Felipe V (1701) su boticario mayor, Luis Riqueur, inició, aunque sin éxito inmediato, los trámites para agregar dos oficios reales (el de la Química ${ }^{40}$ y el de la Destilación) y sus dependientes a la plantilla de la Real Botica $^{41}$. El fallecimiento del destilador mayor, Miguel García de Paredes (1706), propició que la Junta de Obras y Bosques se planteara la extinción del oficio de la destilación siguiendo los criterios que sobre regulación del personal de la Casa Real tomó el decreto de Nueva planta de $1707^{42}$. No obstante, y por tener concedida «la futura» el hijo del destilador fallecido, se accedió a su nombramiento ${ }^{43}$.

Cuando, en 1711, las tropas del bando Austriaco se instalaron en Aranjuez, los empleados de la Real Casa y de los Reales Sitios se encontraron ante el dilema que suponía esa nueva y extraña situación: mantener su fidelidad al Rey con el riesgo que ello implicaba, o permanecer leales a su ciudad y a sus bienes. Concretamente, la Des-

40 GARcía De YÉBEnES TORRES, P.; ANDRÉS TURRIÓN, M.L. (1997) «La introducción de la práctica química en la Real Botica española». Asclepio 49-2. pp. 165-184.

41 Cuando, en 1701, se trataba de poner orden en la nueva plantilla de la Real Casa y Cámara, informaban que, teniendo el destilador mayor de Aranjuez el goce en el real sitio y ochenta ducados de vestuario, sería justo se les mantuviera (a los del oficio) «ínterin» en su empleo, hasta la agregación definitiva al de la Real Botica. Se consideraba también que, llegado este punto, se extinguiría el goce que recibieran. A.G.P.. leg. 3260. Resoluciones sobre criados y dependientes de la Real Cámara de 4 de marzo de 1701

42 La solicitud de Miguel Alfonso García de Paredes para que se le otorgara su título de destilador, como a los demás, desencadenó una revisión de cuentas y gastos de la oficina de Destilación de Aranjuez. Esta «relación del gasto que se causa al año en la destilación de las aguas» transcribía los libros de Veeduría y Contaduría de Aranjuez; va fechada el 20-10-1706 y se desglosaba así:

Salario del destilador, $135.000 \mathrm{mv}$ (3970 rv) más 1.350 rv de las cincuenta fanegas de trigo y cebada.

Salario del ayuda, 4 rv/día.

Gastos de leña y carros, 2.800 rv.

Vidrio, 357 rv.

Acompañando a este texto va una nota firmada por los señores de la Junta, el gobernador de Hacienda, el confesor de S.M. y un tal Torres, aconsejando al Rey que eliminara el gasto antes especificado por su inutilidad, extinguiéndose desde ese momento el Oficio de la Destilación. Dado que la Reina concedió la «futura» de la Destilación a Miguel Alfonso García de Paredes, se proponía le dieran una plaza de ayuda en la Real Botica y, en caso de no haberla, el salario que le correspondiera al empleo de destilador por los días de su vida. A.G.P.. Expedientes personales, 415/31.

43 Le fue concedida la «futura» el 16-4-1706 y fue nombrado destilador mayor el 3-6-1706. A.G.P.. Expedientes personales, 415/31.

A.G.P.. Libro de Registro $n^{\circ}$ 4501. Sumillería de Corps. Extractos de consultas y resoluciones, 17071745. Folios 19 vto y 16 vto.

En principio, se asignó cobrar el sueldo por la Presidencia de Hacienda y, a partir de 1708, comenzó a tener dificultades para recibir el vestuario de ochenta ducados que tenía concedido el cargo de destilador mayor. 
tilación de aquel sitio junto con su jefe inmediato, Miguel Alonso García de Paredes, permanecieron en su puesto y, según voces borbónicas, «teniendo comercio con el bando del Archiduque». Ésto explica el hecho de que, con el regreso de la corte de Felipe V a Madrid y por las razones expuestas, se solicitara con urgencia a la Real Botica la relación de las aguas que se hubieran traído desde Aranjuez para rápidamente eliminarlas ${ }^{44}$. Sin embargo, la destilación continuará funcionando diez años más.

En 1717, el gobernador del Sitio pretendió dotar de una nueva sede a la Destilación, aprovechando los planes de reforma del palacio. Luis Riqueur redactó un memorial informativo (4 de marzo de 1717), a petición del monarca, donde exponía su opinión sobre el oficio de la Destilación, indicando su «insatisfacción en cuanto al funcionamiento de aquella destilación». Se definía claramente a favor del traslado a Madrid, criticaba la baja calidad de las aguas medicinales que llegaban a la Real Botica desde Aranjuez ${ }^{45}$. Expresaba su absoluto rechazo a que el gobernador del

\footnotetext{
44 Miguel de Yto, ayuda de la Botica que servía en las ausencias de Riqueur (boticario mayor), dio una relación de las que se habían tirado. Por orden del sumiller, acatada por el secretario de la Sumillería, se procedió a verterlas en el patio de la Botica, según consta en escrito comunicado a 31 de julio de 1711 . La relación incluía las siguientes aguas que habían sido traídas de Aranjuez en el último viaje de 20 de mayo de 1711:

- 1 redoma de agua de toringil

- idem acederas

- " cardo Santo

- “ escorzonera

- " berdolagas

- " flor de sauco

- " cerezas

- " fresas

- " chicorias

- " llanten

- “ amapolas

- “ borrajas

- " foeniculi

- “ cabecula de rosa

- " rosa castellana

A.G.P.. Leg. 3263.

45 Memorial de fecha 4 de marzo de 1717. El sumiller de corps lo remitía a S.M. el 12 del mismo mes y año. La resolución real recogió la opinión del boticario mayor, mandando decidir si procedía mantener el oficio de la Destilación en Aranjuez. A.G.P. leg. 3265.

«...de ninguna calidad, haciéndose los cocimientos y la oportunidad de tiempos para que salgan del laboratorio con la virtud que se necesita...».

Consideraba que no eran las aguas de utilidad para la medicina: «... aunque así se creyera antiguamente, pues rara es la que puede dar su virtud específica y central por la destilación... cada planta tiene una contextura, requiriendo unas fermentación, otras requieren que sólo se obtengan los zumos, otros hay que destilarlas y otras cocerlas con adicción de aguas mayales, fluviales y fontaneas...».
} 


\section{M. ${ }^{a}$ LUISA DE ANDRÉS TURRIÓN y PILAR GARCÍA DE YÉBENES TORRES}

Sitio pretendiera continuar con el control, casi absoluto, del que era un real oficio. También rechazaba la intención de nombrar como proveedor de plantas y ayuda de destilador a la misma persona ${ }^{46}$. Llegaron a preguntar a Riqueur si convendría dejar que en Aranjuez se prepararan las aguas no medicinales, a lo que respondió que desconocía se hicieran otras aguas, a excepción del vinagre de juncia para rociar los cuartos reales ${ }^{47}$. Exponía, sin paliativos, la inutilidad de seguir en Aranjuez, cuando ya se estaban destilando en Madrid todo lo que precisaban, habiéndose rechazado todas las existentes en Aranjuez para la reposición por inútiles ${ }^{48}$.

Cuatro años más tarde, cuando el proyecto de aquellas nuevas obras de hizo realidad $^{49}$, se observó que el edificio que albergaba el oficio de la Destilación seguía necesitando arreglos. Así, se plantean si una obra que alcanzaría los ochenta o noventa mil rv ${ }^{50}$ sería rentable a la Real Hacienda. Luis Riqueur fue consultado e instado a hacer un análisis del asunto, y partidario absoluto del traslado emitió las siguientes opiniones y peticiones: Solicitó dos o tres piezas contíguas a la Botica, que tiempo atrás habían pertenecido al Consejo de Indias, para construir hornos y salas necesa-

Daba importancia a la ejecución de los procesos en los recipientes adecuados (vasijas de cobre estañado, estaño puro, de baño o sin él): «...las calderas y torres del real sitio, sólo podían conseguir por destilación un húmedo superficial de las plantas, siendo imposible obtener la virtud central...».

En definitiva, se quejaba de que, si los destiladores no tenían el conocimiento apropiado de la botánica: «...se seguirían extrayendo las aguas excrementicias y meramente flemáticas, sin la virtud perfecta que deben tener las aguas».

Con fecha 12 de marzo de 1717 se registra el memorial de Riqueur, mandando S.M. que el sumiller de corps indague la necesidad de un destilador en Aranjuez y con qué salario. A.G.P. Libro de Registro $n^{o}$ 4501. Sumillería de Corps. Extracto de Consultas y resoluciones. 1707-1745. Folio 54 vto..

46 El fallecimiento del viejo proveedor de hierbas, frutos y demás géneros de la Destilación, Gregorio de Bárcenas que, con más de cuarenta años de servicio, se había convertido, sin ostentar ningún nombramiento, en persona de toda confianza del gobernador del real sitio, provocó que desde Aranjuez se pensara nombrar a un nuevo proveedor de plantas que continuara ayudando en la destilación.

47 Informe de Riqueur al Marqués de Montealegre a 28 de marzo de 1717. A.G.P. leg. 3265

48 Por esta razón Riqueur reclamaba se le abonaran 9.403 rv de la consignación a pagar por Aranjuez para la Destilación. A.G.P. Aranjuez. Caja 14142. Expedientes sobre la Destilación.

En agosto de 1747, reinando ya Fernando VI, se expresaba el deseo de S.M. de conocer la causa por la que el Real Sitio de Aranjuez pagaba a la Real Botica de Madrid 6.000 rv, si esta se había trasladado a Madrid en 1721. A.G.P. Caja 14146. Leg 7. Real Sitio de Aranjuez. Médico y Botica. Oficina de Destilación de aguas medicinales.

49 Teodoro de Ardemans, maestro mayor de las obras del Palacio Real de Aranjuez, volvió a revisar la obra del cuarto de levante, donde se situaba la Destilación en 1721. En GonZÁLEZ, A. (1986), El Palacio Real de Aranjuez: Una nueva estructura entre 1626 y 1750. Reales Sitios, 89. Madrid. pp. 57-64.

50 Según consta en la copia realizada por el veedor y contador de la Real Cámara el 16 de diciembre de 1746, del informe solicitado por medio del Secretario del Despacho (Marqués de Campoflorido) a Luis Riqueur, de fecha 21 de enero de 1721, para que informara de lo que le pareciese sobre la forma de trasladar la Destilación de las aguas de Aranjuez. Ordenaban a Riqueur que estudiara los dos últimos quinquenios económicamente para hacer balance de todo, en cuanto a la administración de la Destilación. A.G.P.. Sec. Adm., leg 429. 
rias, corriendo la obra de cuenta de la Real Hacienda (por el maestro de obras de S.M.), así como la de los alambiques y vasijas. Todo ello, calculaban, no alcanzaría los doce mil rv.. Contaba con el traslado de todo el material que el oficio de la Destilación tuviese en Aranjuez. En Aranjuez, y por los caudales de este sitio, se daba leña, carbón, trigo y cebada, datos no considerados en la toma de gastos que tenía la destilación, y considerando el boticario mayor el excesivo gasto de leña y carbón que precisaba el oficio, solicitaba que los 11.558 rv que se decía tenía consignado, se aumentaran hasta $16.000 \mathrm{rv}$, admitiendo que el real sitio sólo diera los $11.558 \mathrm{rv}$ y el resto por la Real Hacienda, pretendiendo no dar cuentas al por menor de la administración de la Destilación, que correría de su parte. Como beneficio económico citaba el ahorro al prescindir del transporte de las aguas. Afirmaba la mayor seguridad y perfecta elaboración de las aguas en la Real Botica.

La Resolución Real que resolvía el traslado efectivo se dictó el 8 de marzo de 1721. De nada sirvieron opiniones encontradas con la del boticario mayor expuestas por importantes cargos rectores y responsables de Aranjuez que trataban de exponer la realidad de que su ciudad era cuna de infinidad de frutas y hierbas necesarias para la elaboración de los destilados ${ }^{51}$. Tampoco fue escuchado el fiscal de la Junta de Obras y Bosques de Aranjuez que acusaba claramente a Riqueur de pretender continuar con la regalía de casa, médico y botica, por el Real Sitio, para la persona que desde Madrid, quedara encargada de recoger y remitir las hierbas medicinales ${ }^{52}$.

Las razones expuestas por Riqueur pudieron sobre las demás. Ese mismo año (1721) comenzaron a construirse los hornos necesarios en las habitaciones del Palacio Real de Madrid que fueron del Consejo de Indias. Un fragmento de la citada Resolución Real ${ }^{53}$, puntualizaba que, vistos los informes, resolvía: Extinción del oficio de destilador mayor. Traslado físico a Madrid, en los términos expuestos por Riqueur, pero teniendo que dar cuentas de los caudales consignados. De los dieciséis mil rv, Aranjuez seguiría contribuyendo con 6.600 rv/anuales, desde primero del año

\footnotetext{
51 El Fiscal de la Junta de Obras y Bosques de Aranjuez, Juan Antonio Samaniego, estudiando los informes y memoriales en pro y en contra del traslado, hizo una exposición de las circunstancias, a favor o no, para evitar un perjuicio económico a la Real Hacienda. Desde Aranjuez se abogaba por el mantenimiento en el real sitio, como hasta ahora y desde hace ciento cincuenta años, resaltando el bajo costo de yerbas y plantas, con un gasto total de 600 Ducados anuales (3.000 rv en material y plantas, y 300 Ducados de sueldo al boticario examinado destilador); sin embargo el arreglo de la Destilación se elevaba a 80 o 90.000 rv, estimados por el Gobernador del sitio, aunque por otros, sólo se consideraban 150 Doblones para establecerla en el lugar de la Armería.

Entre las yerbas existentes en el Sitio se nombraban: «Borraja, Chicoria, Acederas, Berdolagas, escorzonera, Cantueso, Hisopo, Ruda, Peonia, Tila, Grama, escordio, fresas, guindas, y otras infinitas... y todas acabadas de arrancar de los árboles y campos...».

A.G.P. Aranjuez. Caja 14142.

52 Contestación que el fiscal de Aranjuez daba al Marqués de Grimaldo, el año 1722. A.G.P. Aranjuez. Caja 14142.

53 Resolución del traslado de la Destilación de 8 de marzo de 1721. A.G.P.. Sec. Adm.. leg. 429.
} 
1722. El resto se pagaría por la Tesorería Mayor de Hacienda. Se utilizarían dos o tres habitaciones, que pertenecieron al Consejo de Indias, próximas a la Botica, estando cerca del patio de la fuente de la botica, con lo que el surtimiento de agua sería fácil; el gasto de la obras se cargarían al maestro de obras de S.M. y el material (alambiques...) por cuenta de S.M. ${ }^{54}$.

Figura 4. Fechas clave en la evolucion de la Destilacion.

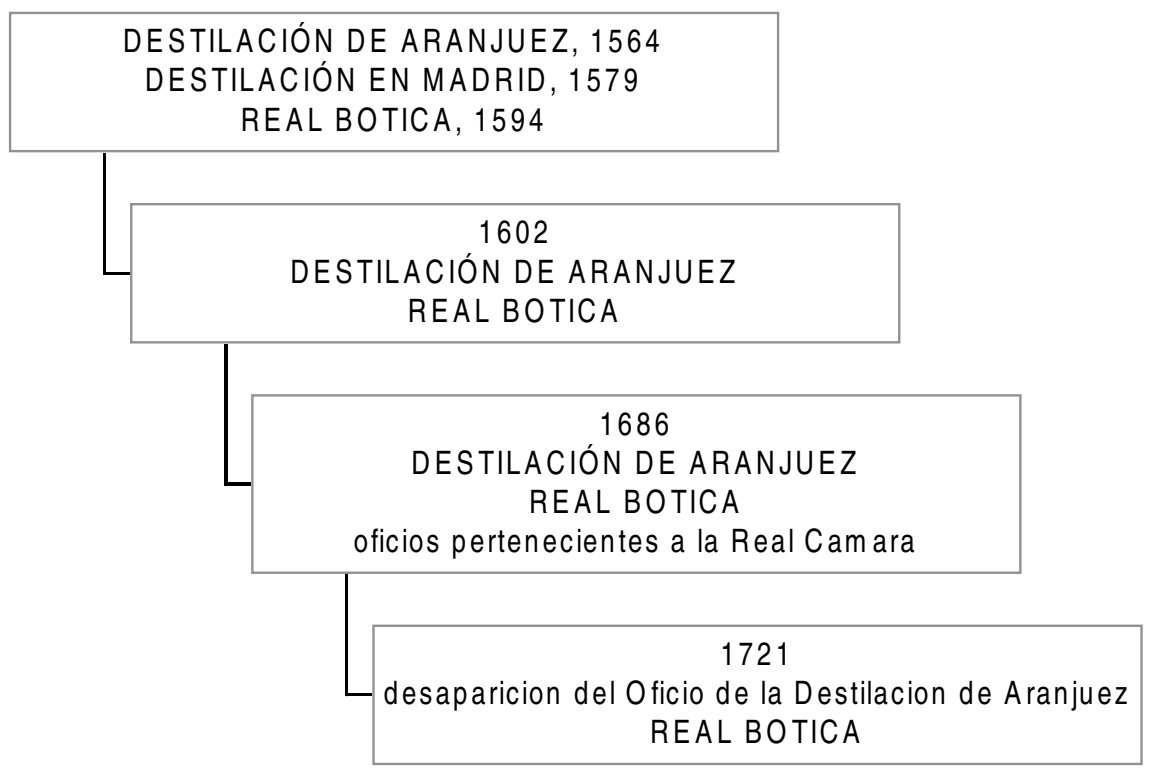

\section{EL TRABAJO DE LA DESTILACIÓN DENTRO DE LA REAL BOTICA}

En los primeros años después de la anexión del oficio de la Destilación por la Real Botica, los gastos ocasionados por los trabajos propios de las destilaciones se detallaron separados del resto de gastos de la Real Oficina. En los pliegos de estas cuentas, en los que se detallaba la data (gastos), el cargo (ingresos presupuestados) y el alcance

54 Comunicación del Marqués de Campoflorido al Marqués de Montealegre. 1721.

En el año 1721, el Marqués de Campoflorido comunicaba al Marqués de Villena la localización en las habitaciones que fueron del Consejo de Indias, corriendo la construcción de los hornos necesarios por parte del maestro de obras de S.M.. A.G.P.. Sec. Adm.. leg. 631. Empleos de la Real Casa. Destiladores de Cámara. 
(cantidad a favor o en contra de la Real Hacienda), se reflejan pagos a personas por su trabajo específico en tareas de este oficio, las cuales podían ser boticarios o no.

El cargo de Destilador Mayor desapareció junto al oficio de la Destilación. El jefe de la Real Botica ostentaría los títulos de boticario mayor y destilador mayor, así como el de espagírico mayor.

Figura 5. Amortizacion de las plazas de ayuda de la destilación en la Real Botica.

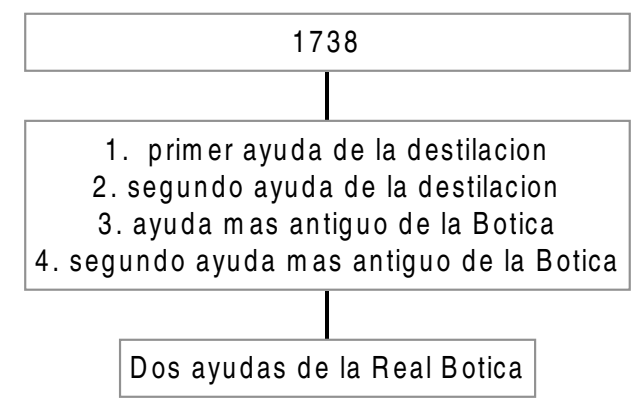

Las plazas de ayuda de la destilación se incorporaron a las existentes en la Botica $^{55}$, y es en el año 1738 cuando S.M. resolvió que las dos plazas de la destilación se

55 Aparentemente sólo una persona de la destilación se vio afectada por el traslado de ésta a la Real Botica: Pedro Verdugo. En el año 1721 ocupaba el cargo de ayuda de la destilación y, obligado a desplazarse y residir en Madrid, en el año 1724 solicitó la permuta de su puesto con el boticario del Real Sitio de Aranjuez; de esta forma volvía a residir en Aranjuez. Para proceder a autorizar la solicitud, los jefes de la Casa Real consultaron distintas personas. Luis Riqueur, como boticario mayor, en respuesta enviada al Conde de Peñaranda (Informe del conde de Peñaranda que reflejaba las opiniones de Riqueur, de 14 de diciembre de 1723. A.G.P. Leg. 3416. Luis I), no encontraba inconveniente en el intercambio, siendo ambos de buenas costumbres y aprobados y examinados por el Protomedicato, no suponiendo aumento de gasto para la Real Hacienda, señalando el salario de Alcoba en 3.180 Rv./año en las arcas de Aranjuez y 24 fanegas de trigo anuales; Verdugo, como ayuda de la destilación, tenía el goce de 4 Rv./día, con obligación de residir en Madrid, especialmente en primavera y otoño.

En mayo de 1724 Manuel de Alcoba, boticario de Aranjuez, era autorizado a ejercer el oficio de ayuda de la destilación de las aguas que ejercía Pedro Verdugo, cobrando 3.080 Rv./año y permitiéndosele continuar los 40 ducados que gozaba en concepto de aposento. El mandato real fue que se cambiaran los empleos, no los sueldos, y cada uno seguiría lo que tenía señalado antes de la permuta. Escrito dirigido probablemente al gobernador del Real Sitio de Aranjuez. Estos dos boticarios efectuaron la permuta bajo consentimiento real, pasando Verdugo a ser boticario del real sitio, por el traspaso de la botica propiedad de Alcoba. A.G.P. Leg. 3414. Luis I.

En virtud de la aprobación de la permuta, juró Manuel de Alcoba el empleo de ayuda de destilador el 28 de marzo de 1724, en manos del sumiller de corps, el Marqués de Astorga. Asientos de la clase sanitaria. A.G.P. Leg. 3418. Luis I. Libro 5. 


\section{M. ${ }^{a}$ LUISA DE ANDRÉS TURRIÓN y PILAR GARCÍA DE YÉBENES TORRES}

agregaran a dos plazas de ayudas de la Botica, las más antiguas, asistiéndolas a cada una con el goce de 3 rv/día en los gastos de la Furriera y los caudales de la Destilación ${ }^{56}$. Se amortizaban así, catorce años después de la desaparición del oficio de la destilación, las plazas que quedaban remanentes de él.

Veinte años después de la absorción, el trabajo que ocasionaba ocuparse de las destilaciones llevó al sumiller de corps a conceder un aumento de sueldo a empleados de la Botica: a los dos ayudas más modernos, 100 Ducados anuales, y a los dos mozos de oficio más modernos, 50 Ducados anuales. Los trabajos de la destilación se realizaban alternativamente y por semanas; en realidad fue una forma de igualar salarios entre los empleados de la Botica, ya que había otros puestos que recibían compensación por trabajos en la química, etc ${ }^{57}$.

Aunque la Real Botica se encargó de las destilaciones, siguió recibiendo caudales destinados a cubrir los gastos que estas manipulaciones pudieran ocasionar. Los boticarios mayores presentaron las cuentas de la Botica y la destilación separadamente, con cargos, alcances y fenecimientos diferenciados. Sólo disponemos de cuentas desde que los oficios se fusionaron hasta 1736.

Para el estricto control de las cuentas de la Destilación no era preciso el visto bueno del primer médico de Cámara (primer protomédico), requisito imprescindible en el proceso de fenecimiento de las cuentas de la Real Botica. Así pues, una vez firmadas por el boticario mayor, por meses, pasaban al sumiller de corps (jefe de la Real Cámara) y al secretario de la Cámara. El sumiller entregaba los pliegos de cuentas, sumados y firmados al mayordomo mayor (jefe de la Casa Real). Posteriormente el contralor las fiscalizaba de nuevo y el grefier daba certificación del alcance final aprobado.

A partir de $1737^{58}$ no se presentaron por separado las cuentas de gastos de la destilación. El dinero de la Destilación se gastó básicamente en la compra de plantas y frutos, material de vidrio y barro, trabajos de calderería, paños, leña. Antes de ser anexionado, el oficio de la Destilación recibió suministros gratuitos desde otros oficios y/o diferentes posesiones reales: oficio del guardajoyas, oficio de la cerería, mercader de S.M., real sitio de Aranjuez, Casa de Campo. Los proveedores fueron

56 El Duque de Frías lo comunicaba en Madrid a 12 de mayo de 1738. A.G.P. Libro de Registro $n^{o}$ 4501. Sumillería de Corps. Extractos de consultas y Resoluciones. 1707-1745. Folio 88.

57 Comunicación del sumiller de corps, de 8 de marzo de 1742. A.G.P.. Sec. Adm.. leg 429.

En ciertos documentos se nombran como empleados de la destilación a partir de dicho año, a personas que no realizaban un trabajo específico de destilación, sino que recibían cantidades de dinero, salarios, consignados como procedentes del extinto oficio. Así, Bartolomé Pérez Durán, en el año 1736, es nombrado como ayuda más antiguo destinado en la Destilación, recibiendo una ayuda de 100 Ducados anuales por los gastos en el oficio de la Furriera. A.G.P.. Exp. Personales. Caja 818/15.

58 En este año fallece el que fue boticario mayor de Felipe V desde su llegada al trono, Luis Riqueur, y ocupa la plaza de jefe de la Real Botica Bartolomé Pérez Durán, primero de forma interina y en propiedad a partir de 1738 . 
jardineros, herbarios, fruteros, caldereros, vidrieros, alfareros, comerciantes ubicados en la zona centro española (principalmente Madrid y provincia).

Si hubo o no una utilización correcta de los caudales que se siguieron entregando por la Tesorería Real y por el patrimonio de Aranjuez, es algo difícil de concretar. Sin embargo, en el año 1742 se resolvió la primera parte del contencioso entre el nuevo boticario mayor y el segundo en el escalafón primer ayuda de espargírico. Este pleito se inició cuando Pérez Durán llega al puesto de jefe de la Botica y trata de poner orden en lo que consideró «prácticas irregulares»; entre ellas el repartir «el sobrante» de los caudales de la destilación entre los empleados de la Real Botica. El boticario mayor consideró que el dinero era de la Real Hacienda y en ella debía revertir o en beneficio de la Botica. Como ya hemos mencionado en el año 1742 confirmaron la legalidad del reparto pues, aunque no hubo orden ni decreto que la aprobara expresamente, quien calla otorga. Todo ésto nos hace preguntarnos cómo es posible que se hicieran pliegos sobre gastos de la destilación si el dinero era repartido.

A partir del 1 de septiembre de 1743 ya no se hicieron diferencias en los caudales que recibió la Real Botica, consignándose 72.000 rv anuales sin hacer mas referencia a la Destilación.

VII. Personal De la Destilación. Destiladores Mayores y AYUdAS DE DESTILADORES

\begin{tabular}{||l|l|l||}
\hline \multicolumn{2}{|c|}{ EMPLEADOS DEL OFICIO DE LA DESTILACIÓN } \\
\hline \hline \multicolumn{1}{|c|}{ NOMBRE } & FECHA INICIO/ PERÍODO & \multicolumn{1}{|c|}{ EMPLEO } \\
\hline \hline Holbeque, Juan & 1564 a $1573(+)$ & $\begin{array}{l}\text { destilador sin nombramiento } \\
\text { en Aranjuez }\end{array}$ \\
\hline Holbeque, Francisco & 1564 a 1565 & $\begin{array}{l}\text { destilador sin nombramiento } \\
\text { en Aranjuez }\end{array}$ \\
& 1565 a 1567 & $\begin{array}{l}\text { Aranjuez } \\
\text { destilador contratado en }\end{array}$ \\
& 1567 a $1595(+)$ & $\begin{array}{l}\text { destilador real en Aranjuez } \\
\text { destilador real en Madrid }\end{array}$ \\
\hline Forte, Giovanni Vicenzio & 1579 a $1601(?)$ & $\begin{array}{l}\text { ayuda de destilación en Aran- } \\
\text { juez }\end{array}$ \\
\hline Valle, Juan del & 1582 a - & ayuda en Aranjuez \\
\hline Sanchois, Juan de & 1582 a $1597(+)$ & destilador real en Aranjuez \\
\hline Santen (Sancten), Juan & 1595 a $1598(?)$ & \\
\hline
\end{tabular}


M. ${ }^{a}$ LUISA DE ANDRÉS TURRIÓN y PILAR GARCÍA DE YÉBENES TORRES

\begin{tabular}{|c|c|c|}
\hline \multicolumn{3}{|c|}{ EMPLEADOS DEL OFICIO DE LA DESTILACIÓN } \\
\hline NOMBRE & FECHA INICIO/ PERÍODO & EMPLEO \\
\hline Fraye, Juste & $\begin{array}{l}1595 \text { a } 1598 \\
(11-4) 1598 \text { a } 1598(+)\end{array}$ & $\begin{array}{l}\text { destilador real en El Escorial } \\
\text { destilador real en Aranjuez (a las } \\
\text { órdenes de Juan de Ausnero) }\end{array}$ \\
\hline Ausnero, Juan de & 1598 a $1602(+)$ & destilador real en Aranjuez \\
\hline Forte, Valerio & $\begin{array}{l}1580 \text { a } 1591 \\
1591 \text { a } 1601 \\
1601 \text { a } 1602 \\
1602 \text { a } 1633(+)\end{array}$ & $\begin{array}{l}\text { mozo en Madrid } \\
\text { ayuda en Madrid } \\
\text { destilador en Madrid } \\
\text { destilador en Aranjuez y } \\
\text { Madrid }\end{array}$ \\
\hline López, Horacio & 1598 a $1622(+)$ & ayuda en Aranjuez \\
\hline Brum, Salvador & 1602 a 1628 (jub) & ayuda en Madrid \\
\hline Rufero, Sebastian & $\begin{array}{l}1622 \text { a } 1633 \\
1633 \text { a } 1641 \\
\end{array}$ & $\begin{array}{l}\text { ayuda en Aranjuez } \\
\text { destilador en El Buen Retiro }\end{array}$ \\
\hline Forte, Vicenzio & 1633 a $1659(+)$ & $\begin{array}{l}\text { destilador real en Madrid y } \\
\text { Aranjuez }\end{array}$ \\
\hline Forte, Bernabé & $\begin{array}{l}1628 \text { a } 1653 \\
1634 \text { a } 1661 \\
1661 \text { a } 1672(1675+)\end{array}$ & $\begin{array}{l}\text { ayuda en Madrid } \\
\text { ayuda en Aranjuez } \\
\text { destilador interino en Aranjuez }\end{array}$ \\
\hline Soleta, Julio & $1634 \mathrm{a}-$ & ayuda contratado en Madrid \\
\hline Vidaurreta Sánchez, Antonio de & 1653 a $1664(+)$ & ayuda en Madrid \\
\hline Forte Rios, Bernabé & $\begin{array}{l}1659 \text { a } 1664 \\
1664 \text { a } 1672 \\
1680\end{array}$ & $\begin{array}{l}\text { mancebo aprendiz en Aranjuez } \\
\text { ayuda en Madrid } \\
\text { becado por S.M. para conti- } \\
\text { nuar estudios de destilador }\end{array}$ \\
\hline Forte, Vicente & $\begin{array}{l}1659 \\
1659 \text { a } 1672 \\
1672 \text { a } 1678(+)\end{array}$ & $\begin{array}{l}\text { concesión de la futura de } \\
\text { destilador } \\
\text { destilador real menor de edad } \\
\text { (interino, Bernabé Forte) } \\
\text { destilador real en Madrid y } \\
\text { Aranjuez }\end{array}$ \\
\hline
\end{tabular}


LA OFICINA DE DESTILACIÓN DE AGUAS Y ACEITES DEL REAL SITIO DE ARANJUEZ (1564-1721)

\begin{tabular}{|c|c|c|}
\hline \multicolumn{3}{|c|}{ EMPLEADOS DEL OFICIO DE LA DESTILACIÓN } \\
\hline NOMBRE & FECHA INICIO/ PERÍODO & EMPLEO \\
\hline García de Paredes, Miguel & $\begin{array}{l}1675 \text { a } 1678 \\
1678 \text { a } 1680 \\
1682 \text { a } 1683 \\
1685 \text { a } 1706\end{array}$ & $\begin{array}{l}\text { ayuda en Aranjuez } \\
\text { destilador interino (muerte de } \\
\text { V. Forte) } \\
\text { destilador interino (muerte de } \\
\text { A. Roda) } \\
\text { destilador mayor de S.M. }\end{array}$ \\
\hline Roda, Alberto de & 1680 a $1682(+)$ & $\begin{array}{l}\text { destilador real en Madrid y } \\
\text { aranjuez }\end{array}$ \\
\hline Gadea, Francisco & 1683 a 1685 (jub) & $\begin{array}{l}\text { destilador real en Madrid y } \\
\text { Aranjuez }\end{array}$ \\
\hline Negrón, Francisco & $21-5-1683$ a 1693 & ayuda en Madrid \\
\hline García de Paredes, Miguel Alfonso & $\begin{array}{l}1687 \text { a } 1706 \\
1706 \\
1707 \text { a } 1720\end{array}$ & $\begin{array}{l}\text { ayuda en Aranjuez } \\
\text { concesión de la «futura» de } \\
\text { destilador mayor } \\
\text { destilador mayor }\end{array}$ \\
\hline Hito y Robles, Miguel de & $\begin{array}{l}1693 \text { a } 1721 \\
1724 \text { (jub) }\end{array}$ & $\begin{array}{l}\text { ayuda en Madrid } \\
\text { destilador mayor }\end{array}$ \\
\hline Verdugo, Pedro & $\begin{array}{l}1707 \text { a } 1720 \\
1720 \text { a } 1721 \\
1721 \text { a } 1724\end{array}$ & $\begin{array}{l}\text { ayuda en Aranjuez } \\
\text { destilador mayor interino } \\
\text { ayuda de destilación en la Real } \\
\text { Botica }\end{array}$ \\
\hline Alcoba, Manuel de & 1724 a 1736 & $\begin{array}{l}\text { ayuda de destilación en la Real } \\
\text { Botica }\end{array}$ \\
\hline $\begin{array}{l}\text { (+) muerte } \\
\text { (jub) jubilación }\end{array}$ & & \\
\hline
\end{tabular}

